\title{
De Memorias del subdesarrollo a Memorias del desarrollo: Kafka en la literatura cubana del desencanto
}

\author{
From Memories of Underdevelopment to Memories \\ of Development: Kafka in Cuban Literature \\ of Disenchantment
}

\author{
Yannelys Aparicio \\ ORCID iD: http://orcid.org/0000-0003-3074-8741 \\ Universidad Internacional de La Rioja, España
}

Las novelas de Edmundo Desnoes Memorias del subdesarrollo (1965) y Memorias del desarrollo (2007) describen el mundo de un burgués que no se adapta ni al proceso revolucionario de Cuba en los años sesenta ni al desarrollo de los Estados Unidos en el fin del siglo XX y comienzos del XXI. Totalmente desubicado, el personaje bebe de las fuentes del existencialismo de mitad de siglo XX y tiene muchas similitudes con ciertos personajes animalizados de Kafka, que van perdiendo poco a poco la capacidad de razonar y se convierten en insectos inútiles.

Palabras clave: Literatura Cubana; Edmundo Desnoes; Kafka; Memorias del Subdesarrollo; Memorias del Desarrollo; Existencialismo.

The novels by Edmundo Desnoes Memories of Underdevelopment (1965) and Memories of Development (2007) describe the world of a bourgeois who does not adapt to the revolutionary process of Cuba in the 1960s and to the development of the United States at the end of the $X X^{\text {th }}$ century and the beginning of the XXI ${ }^{\text {st }}$ century. Totally misplaced, the character drinks from the sources of Existentialism of the mid-twentieth century and has many similarities with certain animalized characters of Kafka, who gradually lose the ability to reason and become useless insects.

KeYwords: Cuban Literature; Edmundo Desnoes; Kafka; Memories of Underdevelopment; Memories of Development; Existentialism.

Copyright: (C) 2020 CSIC. Este es un artículo de acceso abierto distribuido bajo los términos de la licencia de uso y distribución Creative Commons Reconocimiento 4.0 Internacional (CC BY 4.0). 


\section{El subdesarrollo a examen}

La idea del subdesarrollo fue trabajada desde los comienzos de la revolución cubana por intelectuales de la izquierda occidental, convirtiéndose, junto a la descolonización y la guerra civil, en uno de los ejes de reflexión de los años sesenta. ${ }^{1}$ La lucha por el desarrollo, la batalla de la modernización, permeó el vocabulario de la opción triunfalista que invocaba el socialismo como vía segura y definitiva de crecimiento, cuando en las décadas anteriores apenas se aludía a esa nomenclatura. Y el hecho real es que Cuba fue un país que hasta los años cincuenta había batido muchos records de progreso. Más tarde, cuando se gestó y propagó la revolución, el nuevo sistema de los años sesenta emprendió acciones modernizadoras en medicina, escolarización, industria, urbanismo y agricultura, pero las medidas colectivistas frenaron el progreso económico anterior, dejando ver solamente algunas cuestiones sociales como la erradicación de la pobreza extrema y el analfabetismo, o la mejora en las condiciones hospitalarias. Se produjo una igualación social y económica de la sociedad, a la baja, arruinando las grandes fortunas, destruyendo la producción a gran escala, las empresas o multinacionales y los enormes réditos del turismo y del ocio. Sin embargo, la euforia con la posibilidad de la utopía fue tal, que la propaganda que el régimen supo mantener durante años atrajo la atención de intelectuales del campo literario, artístico, técnico y económico. Son conocidas las tesis de Mills, preocupado en toda su producción teórica por las relaciones entre historia y poder, por las diferencias sociales y económicas, y por las difíciles combinaciones y fuerzas que mueven la constitución geopolítica del continente americano. En La élite del poder (1956) estudió el lugar de los ensayistas, académicos e intelectuales en las sociedades capitalistas de mitad de siglo, y en La imaginación sociológica (1959) se enfocó en las relaciones entre aspectos biográficos e históricos, teóricos y prácticos, en los estudios relativos a la ciencia de la Sociología. En 1960, y después de visitar la isla mayor del Caribe, vio la luz su obra sobre los pormenores del proceso revolucionario cubano, en la que estudiaba la situación económica del subcontinente latinoamericano y extraía consecuencias del fenómeno recién establecido en la isla, como un ejemplo para tener en cuenta en el futuro, en el sentido de que ni la dependencia del capitalismo estadounidense

1 Rojas, 2009, 43. 
ni la adscripción al bloque socialista (que todavía no había tenido efecto en Cuba) constituían soluciones positivas para el desarrollo de la zona. ${ }^{2}$

Esas propuestas ejercieron un enorme influjo en críticos de toda la década, porque planeaban por todos los elementos constitutivos del subdesarrollo. La novela de Desnoes, Memorias del subdesarrollo, deudora de esa diatriba, es de 1965; la película, de 1968. A raíz de lo expuesto en la obra escrita y la cinematográfica, junto con otras discusiones en paneles y simposios de esos años, el problema del desarrollo se convirtió en uno de los asuntos más estudiados por sociólogos, politólogos, economistas e intelectuales del nuevo proyecto revolucionario. El autor de las Memorias se unía al cúmulo de voces, como ha demostrado Rafael Rojas, pero desde una perspectiva muy personal:

\begin{abstract}
A pesar de que ese ejercicio antropológico era practicado por un escritor revolucionario, desde el lugar y el momento modernizador de la Revolución, en su discurso reaparecían no pocos tópicos de la tradición intelectual ilustrada, liberal, positivista y eugenésica que, desde Europa, había identificado el mundo latinoamericano con la barbarie. La criatura subdesarrollada, según Desnoes, era, ante todo, un sujeto precariamente sentimental. ${ }^{3}$
\end{abstract}

Los tipos que elabora o que describe Sergio, el protagonista de $\mathrm{Me}$ morias en su visión de La Habana, las costumbres y los gestos de los que habla, son subdesarrollados porque el habitante de la isla debe acomodarse a lo que pasa en cada momento y no tiene espacio ni tiempo para exigirse desde el punto de vista de la adquisición, asimilación o creación de cultura. El personaje protagonista de Desnoes en sus dos principales novelas, la del subdesarrollo y la del desarrollo, se asemeja a ciertos tipos de la narrativa del siglo XX, ubicados o emplazados en un espacio descreído, dubitativo, carente de certezas, que coincide con el proceso que llevará en las postrimerías del siglo XX al fin de las ideologías, en una sociedad postindustrial, la del capitalismo tardío, como apuntó Daniel Bell, ${ }^{4}$ en la que el sujeto como entidad estable se ha aniquilado y el individuo se encuentra descentrado, «esquizofrénico», es decir, con una experiencia «de significantes materiales aislados, desconectados, discontinuos, que no pueden unirse en una secuencia coherente». ${ }^{5}$ El personaje de Desnoes, integrado en el

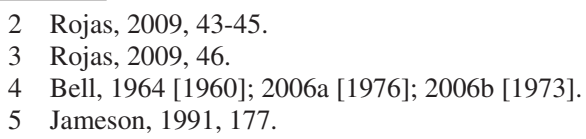


mundo desorientado contemporáneo de las posguerras mundiales y afectado por los cambios que han ocurrido en Cuba a partir de 1959, cuya rapidez e intensidad han sido notorias, es, como dice Astrid Santana, «émulo de Stephen Dédalus, Mersault o de los personajes de Michelangelo Antonioni, cuya composición distintiva como sujetos se traduce en la inhabilidad para acceder a la vida con el lema fáustico de la acción renovadora como principio». ${ }^{6}$

El protagonista de Memorias también se encuentra cercano a otros individuos como Álvaro Mendiola en Señas de identidad, del español Juan Goytisolo, obra muy cercana en el tiempo a la primera de Desnoes, y con una inquietante similitud, la del hombre que observa, que documenta lo que ve o recuerda, y se siente extraño en (o de) su propio país, desplazado e inactivo, dedicado a contar o establecer un vínculo con el pasado. El momento culminante de ese paralelismo es el capítulo VIII de la obra del catalán, en el que Álvaro se encuentra en Montjuich y observa con un telescopio la ciudad de Barcelona mientras combina recuerdos con reflexiones acerca de la decadencia del entorno que le rodea. ${ }^{7}$ Del mismo modo, Sergio, en Memorias, se asoma con frecuencia a ventanas, balcones, e incluso observa a través de unos binoculares ese fluir insulso de la vida fuera de su apartamento, que no es otra cosa que la identificación de lo que ve con lo que siente como propio, es decir, el fluir insulso de su propia existencia. Como veremos más adelante, esta situación de observador panóptico que apunta a un dudoso autoesclarecimiento, en el que «lo exterior y lo interior» ceden poco a poco el paso hacia «lo básico», y la voz va desapareciendo frente a la cada vez más simple actividad instintiva y seminal, acerca a Desnoes a Kafka, otro de los agudos observadores de su tiempo y su lugar, encadenado al espacio de la inactividad.

6 Santana, 2010, 15.

7 La novela de Goytisolo no solo tiene esa evidente coincidencia con la obra de Desnoes por el carácter del protagonista y su situación en el entorno de un país con el que tiene una relación crítica y problemática, sino que está apoyada también en un contexto de relación personal del catalán con el problema cubano. Goytisolo viajó a Cuba por primera vez en 1961 y quedó deslumbrado por el cambio que la isla había dado desde la llegada del nuevo régimen. Apoyó el proceso al principio, pero ese idilio con Cuba no duró demasiado tiempo. Tuvo muy pronto sus diferencias con comunistas de la isla y del exilio español, pero lo que motivó finalmente su desencanto fue el hostigamiento que comenzó a ver en la isla contra los homosexuales, lo que le hizo mantener, desde mitad de los sesenta, una actitud fría con Cuba. En Señas de identidad (1966), se da cuenta de esa evolución, porque el protagonista, Álvaro, cambia de registro desde el comienzo del texto, desde una identificación con el proceso cubano al principio hasta la inclusión de elementos irónicos al final de la novela. Años más tarde, cuando tuvo lugar el caso Padilla, la ruptura con la revolución sería definitiva. 


\section{Un burgués desorientado}

La trayectoria de la narrativa y el cine cubano constituyen un fiel reflejo de los cambios políticos y sociales ocurridos a partir del triunfo del fenómeno denominado «revolución cubana». En este sentido, resulta interesante destacar, como obras representativas, las novelas de Edmundo Desnoes $\mathrm{Me}$ morias del subdesarrollo, publicada en 1965, y Memorias del desarrollo, en 2007. Muy pocas veces se ha dado en América Latina un caso como este: la puesta en escena de dos novelas del mismo autor que, a pesar del extenso período de tiempo transcurrido entre una y otra, hayan conseguido retratar los elementos más cruciales de la sociedad que ambas recrean y representan en las sendas versiones cinematográficas. Memorias del subdesarrollo hace referencia al isleño perteneciente a la clase pequeñoburguesa que, después del triunfo de la revolución, se encuentra completamente desconcertado en su país, y se presenta como espectador pasivo de los primeros pasos del proceso instaurado por el gobierno revolucionario en la isla. En 1968, la novela fue llevada al cine a través de la dirección de Tomás Gutiérrez Alea, con un guion elaborado por Alea y el propio autor del relato, lo que propició que la versión cinematográfica resultase bastante fiel a la novela escrita por Desnoes. Casi medio siglo más tarde, el escritor publica Memorias del desarrollo, que es llevada al cine en el año 2010, bajo la dirección de Miguel Coyula; en ella se relatan aspectos claves de la historia de la revolución cubana y el presente de la sociedad isleña actual: la invasión de la Bahía de Cochinos, la Crisis de los misiles, los sucesos del puerto de Mariel, etc. Una comparación similar se podría hacer, como ya ha apuntado Daylet Domínguez, entre Memorias del subdesarrollo (novela y película) y El rey de La Habana (novela y película), de Pedro Juan Gutiérrez, pues,

ambos proyectos de escritura participan del deseo de localizar un cuerpo colectivo que se asocia a la barbarie y a la decadencia nacional. La novela finisecular relee Memorias desde los lugares de la ciudad, del cuerpo social y las subjetividades marginales. Se perfila en ella además una voluntad de trabajar con el fracaso de los discursos desarrollistas, utópicos y optimistas de la década del sesenta que intentaban delinear una nueva concepción del cubano fuera de los estereotipos que habían prevalecido en la tradición letrada de la isla. ${ }^{8}$

Las novelas de Desnoes recorren ese mismo camino, de la época del triunfalismo a la del fracaso, con la diferencia de que en el caso de los dos

8 Domínguez, 2011, 571. 
textos de Desnoes estamos ante una experiencia que compete a un mismo agente, mientras que la comparación entre Desnoes y la obra de Gutiérrez reproduce procedimientos con un grado más notorio de heterogeneidad.

Al revisar ambas obras de Desnoes (incluyendo las versiones cinematográficas), podría constatarse que se complementan entre sí, permitiendo al espectador formarse una idea bastante precisa sobre el devenir de la sociedad y la política de la revolución. Memorias del subdesarrollo ofrece una vista panorámica de los albores del proceso revolucionario: los inicios de la década de los sesenta, momento decisivo y altamente interesante para el entorno latinoamericano porque, como aseguró Rafael Rojas, la revolución «como espectáculo de ideas de una nueva ciudadanía es descrita como epopeya a imitar, como la vida ejemplar no de un santo o un Mesías, sino de toda una comunidad». ${ }^{9}$ En Memorias, el asunto principal gira alrededor de un desplazamiento que tiene que ver con los cambios que acaban de ocurrir en la isla: el protagonista ha pertenecido al primer mundo porque conoce el modo de vida de los Estados Unidos, y ha tenido una posición acomodada en la Cuba rica de los cuarenta y los cincuenta, pero ahora se encuentra en un país que en un brevísimo espacio de tiempo se ha precipitado y ha caído por debajo de los umbrales del subdesarrollo.

Con respecto a esto, José Miguel Oviedo establece lo siguiente: «El problema de un intelectual perteneciente a un país subdesarrollado es todavía más grande porque un auténtico intelectual nunca es subdesarrollado». ${ }^{10}$ Se trata de una circunstancia que ha sido bastante frecuente en la Cuba de los sesenta, ya que antes de la llegada del régimen revolucionario, había una extendida clase alta o burguesa, incluida aquella a la que pertenecía Edmundo Desnoes, que no establecía una diferencia radical entre el modo de vida que llevaba en Cuba y aquella a la que accedía cuando viajaba con frecuencia a los Estados Unidos. Para los intelectuales, como anota Oviedo, la paradoja que se plantea a partir de 1959 es más apremiante, porque al modo de vida le acompañan hábitos culturales. Los cambios de vida y de perspectiva dejaron una honda huella en Desnoes, que se proyectará en la actitud del protagonista de sus novelas. El cubano confiesa que esa experiencia de haber vivido en muchos lugares, incluso en Nueva York, le obligó a detenerse y asumir su «lugar en el mundo». ${ }^{11}$

9 Rojas, 2009, 29.

10 Oviedo, 1976, 65

11 Desnoes, $1967,7$. 
El protagonista de Memorias del subdesarrollo es dibujado como un individuo que no encuentra su sitio dentro de la nueva sociedad, un forastero en su propio país. El efecto de extrañamiento es absoluto, desde la primera línea de la novela, cuando Sergio confiesa, antes de adentrarse en sus propios procesos identitarios, que todo lo que tenía alrededor, considerado como familiar, cercano, ha desaparecido: «Todos los que me querían y estuvieron jodiendo hasta el último minuto se han ido ya». ${ }^{12}$ Ahora bien, tampoco la Cuba anterior, cerca de los suyos, la que le vio nacer y crecer, era satisfactoria. El autor, por las mismas fechas en las que la primera novela y la película estaban siendo altamente difundidas, manifestaba su propensión al desclasamiento y la desubicación social e incluso étnica, dentro y fuera de su país. En Cuba no se sentía parte de un grupo social asentado e identitariamente definido y consolidado, pero tampoco en los Estados Unidos, a pesar de su tez clara y su ascendencia anglosajona. Efectivamente, ya en 1959 manifestó que había nacido en un ambiente de comodidad, estudiado en un colegio de curas y a sus 28 años ya había tratado por todos los medios de mantenerse al margen de la mediocridad del «cubaneo», y en su primera novela, No hay problema, de 1961, el protagonista, un alter ego temprano de Desnoes, aseguraba que no se sentía cómodo en ninguna parte, porque en Cuba pensaba que era de los Estados Unidos, pero en los Estados Unidos nunca representaría otra dimensión que la del inmigrante. La madre de Edmundo era de origen anglosajón, por lo que en la isla era conocido como «el hijo de la americana», mientras que en el vecino del norte nunca ha dejado de ser un cubano exiliado más. De hecho, él comentó en alguna ocasión que, a pesar de su apariencia anglosajona, nunca dejaría de ser un «negro sureño», insertado, después de su traslado a Nueva York, en una cultura que nunca lo consideraría como propio, porque el gran «sueño blanco de los Estados Unidos» es una «nueva estafa con pretensiones de universalidad». ${ }^{13}$

Y del mismo modo que en el periplo vital de Desnoes, el paso del tiempo no sirve para aquilatar su identidad híbrida y acoplarse al sentido social, político e individual en el entorno de su etapa estadounidense, en el protagonista de sus novelas tampoco hay una evolución integradora, por lo que su mismidad ${ }^{14}$ queda atrapada, como le ocurrirá a los autores de la Generación 1.5 (Gustavo Pérez Firmat, Achy Obejas, Carlos Eire, etc.), en un guion,

12 Desnoes, 2006 [1965], 21.

13 Desnoes, 1967, 100.

14 Fernández Retamar, 1995 [1976], 71. 
un hyphen que separa los dos términos del gentilicio cubano-americano. Sergio Malabre, que no termina de aceptar su condición de marginalidad en su propio país, no es capaz tampoco de cortar con el pasado y enfrentarse con radicalidad a un régimen diametralmente opuesto al que le aseguraba, en su etapa anterior, una posición desahogada y una consideración social beneficiosa. Es más, se alegra en ocasiones de haberse quedado solo, sin familia y sin amigos, con su «nueva libertad-soledad». ${ }^{15}$ Este Sergio, tanto el de la película como el de la novela, simboliza así a esa antigua burguesía anacrónica, que ni avanza para trasladar su modelo ni puede aceptar el sistema que acaba de ser impuesto: el de la desprivatización de las empresas, la propiedad socialista y tantos otros cambios que trajo consigo la revolución. Ahora bien, a pesar de ello, una parte de esa burguesía continuaba ofreciendo una exégesis sentimental del pasado y suponía que el nuevo régimen duraría poco tiempo, restableciéndose así un sistema similar al anterior, fuera democrático o no, pero que respetara la estratificación social que hasta entonces había sido la inspiradora del modelo de sociedad, que manejaba sin complejos ni cortapisas los criterios económicos, culturales, literarios, etc. Cuando el armazón social y cultural existente desde la creación de la República en 1902 desaparece, el cual había mantenido unos estándares de desarrollo francamente aceptables, esa burguesía latente de los primeros años intuye que con el desastre económico llegará igualmente un subdesarrollo que afectará al mundo del arte, la cultura, la literatura y el resto de las manifestaciones espirituales de la sociedad. Ahora los artistas ya no pertenecen a una élite ilustrada que los exime de servidumbres básicas, como el trabajo en el campo o el servicio a la revolución en cualquiera de sus versiones, incluso las más materiales, bajas y humildes. El nuevo orden instaurado suprime las diferencias económicas y pasa por encima de las especificidades laborales, que muchas veces dibujaban asimismo las brechas salariales. Aquellos que comenzaron su obra literaria o artística en los últimos años de la época de Batista, acostumbrados a manejar presupuestos económicos holgados, a realizar viajes al exterior, a conocer al detalle la literatura contemporánea de otros países, a comprar libros extranjeros y obras artísticas en cualquier tienda al efecto, de cualquier ciudad del país, sienten un vacío difícilmente asumible, mientras que aquellos jóvenes de la siguiente generación, que no han consumido arte en tiempos de abundancia ni han estado en contacto con los intelectuales de otros países, asumen

15 Desnoes, 2006 [1965], 22. 
con normalidad el control de ciertos productos, la escasez de otros y la imposibilidad de conocer a los compañeros de generación esparcidos por la geografía americana y europea. La revolución crea sus propios cauces de difusión de productos culturales, orienta los gustos, canaliza modas, controla cantidades y calidades, y produce, en ese gran teatro para la construcción del hombre nuevo, la «escenificación de una utopía en el Tercer Mundo o, más específicamente, en el Caribe, una zona fronteriza donde se capitalizan símbolos turísticos, sexuales, religiosos y revolucionarios como atributos de una comunidad políticamente alternativa». ${ }^{16}$

En Memorias del subdesarrollo (filme y novela), la incertidumbre y la desorientación aparecen como constantes en el personaje que monologa de principio a fin, y giran alrededor de los conceptos de revolución y subdesarrollo, como si una cosa llevara inexorablemente a la otra. Muy acertadamente, Oviedo afirma que «la novela tiene el raro mérito de contemplar la revolución en marcha a través de los ojos de un pequeñoburgués, sin traicionar ni a uno ni a otro». ${ }^{17}$ En este sentido, el mérito de Desnoes consiste quizá en mostrar abiertamente, por primera vez dentro del proceso revolucionario, la preocupación existencial de tantos pensadores cubanos que se enfrentaban a la duda, debatiéndose ante la disyuntiva de vivir entre el pasado y el presente y sin saber exactamente qué rumbo tomar. Como ya anotó Román de la Campa, la ambigüedad esencial de la obra, esa multiplicidad de posibilidades interpretativas, tanto en la novela como en la película de Gutiérrez Alea, no deja indiferente a nadie, porque reproduce contrariedades que tienen un sentido ético. Es más, llega incluso a generar rechazo o simpatía hacia el protagonista por todos esos motivos implícitos en la ambigüedad:

Provoca antipatía como protagonista para quienes buscan el «sujeto revolucionario»: su incertidumbre ante los cambios sociales es explicita. Será visto con simpatía por quienes celebran la ambigüedad existencial como fin en sí, como plasmación de un pluralismo de valores inconexos. Desde una perspectiva más didáctica, la óptica de Malabre cobra gran utilidad en el filme de Gutiérrez Alea, quien la incorpora para contrastarla cambiando la presentación del mundo objetivo encontrada en la ecuación original. Mucho menos útil será para la consideración de que el éxito de la novela y la película se deben a un «equívoco poético»: la simpatía que despierta la revolución cubana ablanda todo juicio crítico. ${ }^{18}$

16 Rojas, 2009, 29.

17 Oviedo, 1976, 66.

18 De la Campa, 1990, 1040. 
Pero, dejando a un lado la multiplicidad aludida, lo que sí consta en última instancia en la obra de Desnoes, con meridiana claridad, es el desasosiego por el futuro de la literatura en un país socialista, subdesarrollado y en plena construcción de una sociedad en la que «todo lo que nos rodea está hundido en el subdesarrollo. Hasta los sentimientos del cubano son subdesarrollados: sus alegrías, y sus sufrimientos son primitivos y directos, no han sido trabajados y enredados por la cultura. La Revolución es lo único complicado y serio que les ha caído en la cabeza a los cubanos. Pero de aquí a que nos pongamos al día con los países civilizados pasarán muchos años». ${ }^{19}$ En este sentido, las reflexiones derivadas del análisis del texto escrito y el fílmico son similares y equiparables en un alcance exclusivamente ideológico o político, tal como han asumido Antonio José Ponte en La fiesta vigilada y Rafael Rojas en El estante vacío, a pesar de la crítica que de esa identificación hace Melo en su artículo de 2017, en el que señala que entre los dos artefactos hay una «paridad inexistente», pero en una orientación más bien de «especificidad textual» y «audiovisual», que podría justificar las diferencias entre ambas obras de arte. ${ }^{20}$

En la década de los sesenta, dentro de la isla, escritores, artistas, pintores y todos aquellos que de una forma u otra estuvieran vinculados con alguna rama de la cultura, se encontraron repentinamente ante una serie de cambios inesperados y veloces, ante los cuales la mayoría emocionada por la singularidad y lo novedoso del nuevo modelo social, se dedicó a apoyar la revolución, simpatizando con ella al cien por ciento y constatando el soporte incondicional en su producción literaria. La intelectualidad cubana se vio ante la necesidad de reconducir sus valores en aras de la construcción del «hombre nuevo». En 1961, se había declarado el carácter socialista de la revolución, por lo que era necesario redefinir los objetivos y direcciones hacia dónde debía dirigirse el pensamiento intelectual: había que llevar la cultura por una senda paralela a la revolución. Lo más importante era, como lo manifiesta Fernández Retamar, que «los intelectuales teníamos que recuperar el tiempo perdido, recuperarnos a nosotros mismos, hacernos intelectuales de la revolución, en la revolución». ${ }^{21}$ Con esta frase, el cubano dejaba establecido que cultura y revolución quedaban unidas en una sola línea.

En la película Memorias del subdesarrollo, el personaje observa, de modo contemplativo, el paisaje político de la nueva Cuba y en su reflexión

19 Desnoes, 2006 [1965], 36.

20 Melo, 2017, 129.

21 Fernández Retamar, 1967, 10-11. 
denota un irónico desasosiego: «Todo sigue igual, aquí todo sigue igual. Así de pronto parece una escenografía, una ciudad de cartón. El Titán de Bronce, Cuba libre e independiente, quién iba a sospechar todo esto, sin el aire imperial [...] ¿y la paloma que iba a mandar Picasso? Muy cómodo eso de ser comunista y millonario en París». Sergio divisa el escenario real, desde su balcón, y nos desvela un punto de vista completamente ajeno al discurso oficial del Jefe de Estado, quien también aparece en el fragmento cinematográfico, cerrando el discurso con la habitual frase de «Patria o Muerte», mientras nuestro protagonista, más que patria, divisa muerte. Como ya observaron Taccetta y Martín Peña, «el film hace dialogar a la civilización y al subdesarrollo operando una síntesis particular en el personaje de Sergio, cuya casa/refugio burgués se convierte en su ventana al mundo. Desde allí, con ayuda de un telescopio, el personaje "mira" el subdesarrollo. Él también es subdesarrollo pero debe comprenderlo como en un acto casi bautismal saliendo como por primera vez, solo, más allá de las puertas de su edificio». ${ }^{22}$ Así, la escena ya aludida del balcón satiriza tristemente las consignas de la revolución: «Esa humanidad ha dicho basta y ha echado a andar, como mis padres, como Laura y no se detendrá hasta llegar a Miami. Sin embargo, todo parece hoy tan distinto, ¿He cambiado yo o ha cambiado la ciudad?» El simbolismo es claro: el cierre de la escena evoca el aforismo kafkiano «una jaula salió en busca de un pájaro». Sergio se dirige hacia sus pájaros que, en el balcón, enjaulados, comienzan a trinar de forma constante. El hombre abre la puertecilla de la prisión para extraer, sin inmutarse, a una de las aves muertas, mientras en el trasfondo va silenciándose, gradualmente, el canto de las aves. Acto seguido, el actor arroja el cadáver del pájaro al vacío, declamando un fragmento de la «canción desesperada» de Pablo Neruda: «Es la hora de partir, oh abandonado como los muelles al alba, todo en ti fue naufragio».

Aves muertas son para los disidentes aquellos que aceptan con resignación las imposiciones, mientras que la ideología oficial identifica al revolucionario con el que sigue al pie de la letra las directrices emanadas por el gobierno, en un proceso que recorre la década de los sesenta y, a comienzos de los setenta, puede denominarse como estalinista. El aparato pone en marcha enseguida una maniobra constante de adoctrinamiento, que borra sin complejos cualquier atisbo de indeterminación. No sería compatible, entonces, declararse revolucionario y, a la vez, empaparse de ciertos

22 Taccetta y Martín Peña, 2006. 
productos que el Estado considerara como contraproducentes. Según Rafael Rojas, «no bastaba con definirse como "socialistas cubanos" y, a la vez, mantenerse interesados en la producción cultural de Occidente: esa legítima posición era vista por sus superiores y por ellos mismos como una contradicción o una ambigüedad». ${ }^{23}$

La discusión sobre la actividad que podían realizar los artistas y sobre las decisiones acerca de lo que se podía o no crear o consumir como productos culturales y artísticos fue un lugar común en los debates de los congresos de finales de los sesenta y comienzos de los setenta, hasta que esa diatriba se cortó en seco después del conocido discurso de Fidel Castro en abril de 1971, en la clausura del Primer Congreso Nacional de Educación y Cultura. Allí, el dictador no hablaba de aprendizaje en general sino de «nuestro aprendizaje», y diferenciaba entre unos personajes que trataron de aparecer como simpatizantes de la revolución y los que sinceramente le ofrecían todo su apoyo, sin condiciones. Y concluía:

Para nosotros, un pueblo revolucionario en un proceso revolucionario, valoramos las
creaciones culturales y artísticas en función de la utilidad para el pueblo, en función
de lo que aporten al hombre, en función de lo que aporten a la reivindicación del
hombre, a la liberación del hombre, a la felicidad del hombre. Nuestra valoración es
política. No puede haber valor estético sin contenido humano. No puede haber un
valor estético contra el hombre [...] Para un burgués cualquier cosa puede ser un valor
estético, que lo entretenga, que lo divierta [...] Pero esa no puede ser la valoración
para un trabajador, para un revolucionario, para un comunista. Y no tenemos que tener
ningún temor a expresar con toda claridad estas ideas. ${ }^{24}$

Desnoes nunca aceptó sin vacilación los presupuestos dictados por la cúpula, pero tampoco se enfrentó siquiera de forma indirecta al conjunto de las directrices del gobierno de la dictadura. Trabajó siempre en los márgenes de la ambigüedad y de la ironía, razón por la cual las primeras Memorias fueron acogidas por algunos con entusiasmo, si la obra se interpretaba como un texto que mantenía una postura profundamente crítica con la dejadez de la burguesía que todavía habitaba en los contornos periféricos del sistema, mientras que otro grupo de lectores y críticos aseguraba que esa obra constituía una deconstrucción del fenómeno que se autodenominaba revolución, pero que no era más que una dictadura de las muchas que habían asolado América Latina en el último siglo.

23 Rojas, 2009, 51.

24 Edwards, 2015 [1973], 68-69. 
Lo cierto es que el protagonista de la novela del subdesarrollo analiza la sociedad en la que vive, sin ofrecer un juicio taxativo y claro, pero también se autodeconstruye, sobre todo en las escenas en las que, solitario, vaga por interiores: «Me da una sensación extraña al caminar por las habitaciones; la casa se está convirtiendo en una caverna». ${ }^{25}$ Malabre comienza con observaciones más generales acerca de su relación con el entorno, pero termina por descender hasta su propio cuerpo, que es analizado miembro por miembro: «Fijándose en los pies uno ve que está muy cerca, que es un animal». ${ }^{26} \mathrm{~A}$ partir de aquí, la sensación de extrañamiento frente al medio e incluso frente a sí mismo recuerda progresivamente al universo generado alrededor de la cucaracha de La Metamorfosis de Kafka.

\section{Kafka en La Habana, Gregor y Sergio, la voz perdida}

Los elementos civilizatorios del hombre, como pueden ser sus ojos, que observan y ordenan; los pies, que enmarcan el ambiente exterior y lo pueblan; o las manos, que convierten las materias primas en elaboradas, y pueden manifestar las emociones a través de la intensidad y el cariz del tacto, abandonan paulatinamente su principal y más elevado cometido para situarse en los niveles básicos y absolutamente desprovistos de sutileza. Algo parecido pasa más adelante con algunos escritores que avanzan por una línea crítica de la sociedad que les ha tocado padecer, y que recuerdan a los procesos de animalización kafkianos. Muy conocido es el texto de Arenas (1983) sobre Piñera en el que las cucarachas están relacionadas con el hostigamiento, con la implantación de un panóptico desde el que se observa a todos los bichos, como indeterminados, incapaces de producir material libre. Las cucarachas cubanas van más allá, según Arenas, de Gregor Samsa, porque el cubano sufre la persecución, pero es que además «la habita», y ha hecho de ella «un modo de vida o de sobrevida». ${ }^{27}$ Hay una cierta desviación en Arenas desde el sentido más existencial de la animalización kafkiana, y de la de Desnoes, al meramente político. Y en un cuento de Rolando Sánchez Mejías, «Diez mil años», la animalización va acompañada de personajes afines al contexto kafkiano, cuando un narrador, cubano, imagina el modo de concebir una versión de La metamorfosis en la

25 Desnoes, 2006 [1965], 30.

26 Desnoes, 2006 [1965], 25.

27 Arenas, 1983, 20. 
que el amigo de Kafka, Max Brod, escucha desde el otro lado de la pared la voz del escritor que evoluciona desde el sonido humano al bestial, y lo encuentra después convertido en un insecto inhumano y descomunal. ${ }^{28}$ Es decir, la transformación supone, en el caso del relato del Sánchez Mejías, una circunstancia que se encuentra ligada a una secuencia más expresiva que performativa, por lo que se instala dentro de un contexto en el que naturaleza y lenguaje, razón y lenguaje, identidad y lenguaje, van íntimamente unidos, como ya afirmó Aristóteles:

consta ser el hombre animal político o civil muy más de veras que las abejas, ni que ningún otro animal que va junto en manadas; porque, como ya está dicho, la Naturaleza ninguna cosa hace innecesaria y, entre todos los animales, solo el hombre tiene uso de razón y de lenguaje. Porque la voz es indicio de la pena o deleite que se siente [...] El lenguaje es para demostrar lo que es provechoso y lo que es perjudicial y, por la misma razón, lo que es justo e injusto. Porque esto es peculiar de los hombres y distinto de los demás animales. ${ }^{29}$

La racionalidad humana es un elemento constitutivo que opera en dos potencias: el entendimiento y la voluntad. Esta máxima aristotélica es explicada de forma conveniente por Tomás de Aquino en la Summa, y ha sido recientemente puesta al día por José Alpiniano García-Muñoz en su obra El tomismo desdeñado (2012). «El apetente intelectual — dice el filósofo tomista colombiano - no cesa de apetecer por conocer las cosas, esto es, por captar su correlatividad, interdependencia o concausalidad en el orden físico». ${ }^{30}$ Es decir, la función intelectual no se agota en el juicio hacia lo externo o hacia uno mismo, sino que se extiende hacia el apetito intelectual, por el que el entendimiento se mueve hacia la verdad o realidad captadas, en la medida en que son útiles y atractivas para él. En el transcurso de las escenas tanto de la novela de Desnoes como de la película, se observa que el protagonista maneja sus funciones intelectuales de modo pleno al comienzo de los dos textos, realiza juicios cabales y se adhiere a aquellos bienes que considera beneficiosos, dentro de las posibilidades que le otorga el sistema. Sin embargo, conforme avanza la historia, el entendimiento y la voluntad de asociarse a lo útil en Malabre se van malogrando paulatinamente, y las reacciones del protagonista adquieren visos de animalidad. Hay una sección de la novela en la que Sergio es consciente del deterioro paulatino de

28 Sánchez Mejías, 1993, 8.

29 Aristóteles, 1910 [s. IV a. C.], 15-16.

30 García-Muñoz, 2012, 151. 
esas funciones superiores, y recapacita: «Como no hay nadie en casa no me aguanto nada. Me acordé de mi padre soltando peos y eructando solo en el portal los domingos [...] No puedo permitir que esto vuelva a pasar. Aunque no haya nadie en la casa debo comportarme como un hombre civilizado. Me avergonzaría terriblemente que alguien hubiera oído mi eructo de bestia satisfecha». ${ }^{31}$ Ahora bien, llega un momento en que las potencias superiores ingresan en un estado de letargo, producto del tipo de vida que el régimen le ha abocado a llevar, por lo que el nivel racional desaparece, fagocitado por el predominio del instinto y las pasiones, que pertenecen a un nivel inferior de conocimiento y acción. Desnoes se instala, de esa manera, en un ámbito que ya habían explorado décadas antes los miembros de generaciones literarias precedentes, y que conectan con ciertas actitudes nihilistas y existencialistas de la posguerra mundial, como ya lo ha datado Rafael Rojas:

Orígenes se debatía entre el horror vacui de Pascal y la nada que fluye de Nietzsche. Dos alternativas plenamente inscritas en la deconstrucción de la razón occidental: el AntiDescartes y el AntiHegel, descritos por Albert Camus en El hombre rebelde, cuyo fragmento sobre el nihilismo fue traducido por Rodríguez Feo para un número de 1952. Esta plataforma [...] permitió ciertas aproximaciones al existencialismo y, en especial, a Martin Heidegger, de quien Piñera Llera tradujo el pasaje de ¿Qué es la metafísica? en el verano de 1949. ${ }^{32}$

Edmundo Desnoes, que comienza a escribir muy poco antes del triunfo de la revolución, cuando el existencialismo ya se ha asentado en el mundo occidental, procedente sobre todo de Francia, recibirá una huella clara de la versión sartreana del movimiento, cercana a la «nada que fluye» que cita Rojas, adoptada desde Nietzsche por los filósofos galos de moda en esas décadas, que dejarán una impronta considerable en los cubanos de los sesenta, ${ }^{33}$ y asimismo en muchos autores de países europeos y americanos. ${ }^{34}$

La huella del escritor checo en el campo literario latinoamericano ha sido fecunda desde hace casi un siglo. Los trabajos de varios críticos y escritores de los últimos años así lo corroboran. ${ }^{35}$ Se ha hablado de cuatro

31 Desnoes, 2006 [1965], 31.

32 Rojas, 2008, 296.

33 Menton, 2002, 410 .

34 Jiménez, 2011.

35 Arenas, 1983, sobre Piñera y Kafka; Yelin, 2010, sobre Kafka en Argentina; Arce, 2016, sobre Kafka en Antonio di Benedetto; Varela, 2007, sobre animales en Kafka y Benedetto; Yelin, 2015, sobre la recepción de Kafka en la crítica y la literatura hispanoamericana; Grabatzky, 2017, sobre Kafka en Cuba a finales del siglo XX; y Martínez y Yelin, 2013, sobre la recepción crítica de Kafka en las dos orillas. 
fases en la recepción de Kafka en el mundo hispánico: la primera, de descubrimiento de su obra, con las primeras traducciones (1927-1945); la segunda, su inclusión en revistas y editoriales latinoamericanas (1945-1965); la tercera, la reactivación en la crítica española y en la teoría literaria (19651983), y la cuarta, años de menor atención crítica (1983-1999). ${ }^{36}$ En el contexto de Cuba, la primera aproximación crítica memorable fue la de Virgilio Piñera, con su artículo «El secreto de Kafka» en Orígenes en 1945, en el que valoraba sobre todo su estilo, su forma de «hacer» literatura, por encima de los contenidos, y llegaba a la conclusión de que quizá los lectores de ese momento no estaban preparados para digerir sus innovaciones, más propias de la mitad del siglo XXI. Ya en los años ochenta, algunos autores del entorno de la revista Mariel y Diáspora(s), como Reinaldo Arenas, Rolando Sánchez Mejías o Carlos A. Aguilera, volvieron sobre el checo partiendo de Piñera y relacionando los ambientes opresivos de los relatos kafkianos con las consecuencias de la dictadura cubana y los regímenes de estilo soviético. ${ }^{37}$

En Desnoes, el background kafkiano pervive en las Memorias del subdesarrollo, pero permanece asimismo en la novela del desarrollo, publicada cuatro décadas más tarde. En ella, el protagonista, un alter ego tanto de Edmundo como de Sergio Malabre, denominado ahora Edmundo (Sergio Garcet en la película), repasa su experiencia vital en el exilio, y repite patrones ya manejados en las primeras Memorias, signados por la abulia, la desesperanza y el escepticismo propios de un hombre que está viviendo sus últimos días, y su identidad se ha visto dañada por el cambio y la inadaptación. Es interesante señalar que, si se leen ambas novelas de forma consecutiva, como dos partes de la misma historia, podrían detectarse relevantes similitudes entre el protagonista de Memorias del subdesarrollo/desarrollo y el personaje principal del relato La Metamorfosis, de Franz Kafka. Desde la primera novela, la reflexión del personaje recuerda a Gregor Samsa, al despertar convertido en un enorme cucarachón: «esta mañana me asombró el eructo tan ruidoso que solté cuando terminé de tomar el café con leche $[\ldots]$, me estoy convirtiendo en un animal». ${ }^{38}$

De la misma forma en que Samsa, convertido en insecto, contempla el horizonte que le rodea a través de la puerta abierta de su dormitorio, Sergio, desde su piso de La Habana, es testigo presencial de la «construcción

36 Martínez y Yelin, 2013.

37 Garbatzky, 2017, 49.

38 Desnoes, 2006 [1965], 31. 
del socialismo»: véase la escena en la que Corrieri observa detenidamente el panorama de su ciudad a través de los binoculares, mientras, a manera de documental, se presenta un discurso del máximo líder de la revolución: «Nosotros sabemos lo que hacemos, y sabemos cómo debemos defender nuestra integridad y nuestra soberanía [...] Patria o muerte, venceremos". Acto seguido, Sergio, desorientado, examina los rostros desconocidos de sus paisanos mientras se pregunta: «¿Qué sentido tiene la vida para ellos? ¿Y para mí? ¿Qué sentido tiene para mí?» Tal y como sucede en La metamorfosis, a medida que avanza la narración, el personaje va perdiendo voz, a la vez que da rienda suelta a sus instintos y placeres naturales. La transformación de los personajes evoluciona de forma similar: al descubrirse convertido en un enorme cucarachón, Samsa desarrolla monólogos interiores, y reflexiona acerca de su situación actual: «Eso de levantarse pronto, pensó, le hace a uno desvariar. El hombre tiene que dormir». ${ }^{39} \mathrm{De}$ igual manera, en Memorias del subdesarrollo, el protagonista, abandonado por Laura y separado de sus padres, monologa reflexionando acerca de la vida y el destino: «Todos los que me querían y estuvieron jodiendo hasta el último minuto se han ido ya [...] Creo que Laura estaba medio arrepentida de haberme dejado [...] En cuanto le resuelvan sus problemas - y no tiene muchos- se olvidará de mí». ${ }^{40}$

Paulatinamente, tanto en La metamorfosis como en Memorias del subdesarrollo, los protagonistas irán olvidando sus preocupaciones. Gregor dejará atrás los pensamientos acerca de las exigencias de su jefe, olvidará las responsabilidades ante las deudas de sus padres, la lucha ante la premura por levantarse de la cama para acudir al trabajo y así cubrir los gastos de su familia, etc. Las prioridades del personaje se transforman radicalmente, poco a poco dejará de pensar en solventar las necesidades económicas de la familia, para dar paso a nuevas inquietudes: «Las patitas de Gregor zumbaban cuando se acercaba el momento de comer [...] Había verduras pasadas medio podridas, huesos de cena, rodeados de una salsa blanca que se había ya endurecido [...] a toda velocidad, y con los ojos llenos de lágrimas de alegría, devoró el queso, las verduras y la salsa; los alimentos frescos, por el contrario, no le gustaban». ${ }^{41}$

De la misma manera, Sergio Malabre se encuentra mejor entre las cosas que entre sus iguales: «Prefiero los objetos a las personas. Por eso

39 Kafka, 2001 [1915], 134.

40 Desnoes, 2006 [1965], 21.

41 Kafka, 2001 [1915], 153-154. 
no me siento tan solo en la casa: los sillones, los libros, la cama, las sábanas limpias, el refrigerador, la bañadera con agua fría y caliente, el azúcar, el café, los cuadros y todo lo que hay regado por los cuartos — todo eso me acompaña». ${ }^{42}$ Es más, incluso los movimientos más espirituales, como el del amor, están signados, en este proceso de animalización, como en Samsa, por la apetencia simple y básica de la comida. Sergio, que está recordando a Anita, con su franca belleza, reflexiona sobre el rechazo que le produce imaginar que la barriga de la persona deseada está llena de frijoles, porque en Cuba ya no existe la abundancia de otras épocas. Eso supone «un golpe mortal para mi visión romántica del amor» — dice-, y concluye que si en vez de frijoles negros «hubiera sido pato trufado, galantina de faisán, salmón, suflé de queso, yo no sé, hasta pastel de manzana o gelatina de frambuesa, cualquier cosa menos frijoles negros, no me hubiera roto la Weltanschauung». ${ }^{43} \mathrm{El}$ proceso de degradación queda así relacionado con uno de los tres supuestos que Garbatzky asocia a la animalización. Se trata, según él, de la «creación de un interregno, un pequeño territorio paralelo, subterráneo o por fuera de la luz», ${ }^{44}$ en el que la existencia del animal (o lo animalizado) «exige la invención del margen, los recovecos donde pueda existir e incluso donde pueda visualizarse furtivamente, brillar». ${ }^{45}$

La voz en declive, trasladada a los subterráneos y fundada sobre nuevas lógicas de los personajes, podría en tal caso estar estrechamente vinculada con la identidad. Sergio no encuentra prácticamente ningún aspecto en común con los individuos de su entorno: «Cada vez que veo a una mujer bonita no puedo dejar de mirarle furtivamente la barriga y preguntarme ¿Qué habrá comido hoy? [...] Eso ocurre con todo lo que nos rodea, está hundido en el subdesarrollo. Hasta los sentimientos del cubano son subdesarrollados: sus alegrías, y sus sufrimientos son primitivos y directos, no han sido trabajados y enredados por la cultura». ${ }^{46}$

La actitud de Sergio conecta con Samsa, que desde su encierro reflexiona acerca de la vida de los otros, sus parientes, de quienes parece dejar gradualmente de sentirse parte: «iQué vida tan apacible lleva la familia [...] se sintió muy orgulloso de haber podido proporcionar a sus padres la vida que llevaban [...] ¿qué ocurriría si toda la tranquilidad, todo el bienestar,

42 Desnoes, 2006 [1965], 34.

43 Desnoes, 2006 [1965], 36.

44 Garbatzky, 2017, 51.

45 Garbatzky, 2017, 52.

46 Desnoes, 2006 [1965], 36. 
toda la satisfacción, llegase ahora a un terrible final?». ${ }^{47} \mathrm{El}$ denominador común parece ser la pérdida del habla como elemento comunicador en los personajes, ${ }^{48}$ quienes, al no poder utilizar la palabra para hacerse entender entre los suyos, dejarán de formar parte de un núcleo del que, hasta la fecha, habían constituido un elemento clave: «Si Gregor hubiese podido hablar con la hermana [...] hubiese soportado mejor sus servicios, pero de esta forma sufría con ellos».49

En ambas obras, cuando los protagonistas refieren decisiones importantes relacionadas con su identidad, son generalmente aquellas que han sido tomadas en el pasado, de ningún modo en el presente. Al sentirse abandonado, el personaje de Memorias del subdesarrollo hace balance de sus errores en el matrimonio: «El comemierda he sido yo, que trabajé para mantenerla, como si hubiera nacido en Nueva York o París - y burguesa, como dicen aquí ahora- - y yo en esta isla subdesarrollada, entreteniéndola, llevándola a países civilizados, tratando de refinarla, haciendo un tremendo esfuerzo [...] Logré que aprendiera a vestirse y a leer novelas norteamericanas y francesas [...] Ella era un animalito [...], un animalito de lujo». ${ }^{50}$

Hacia la mitad de las historias, en ocasiones Gregor y Sergio reflexionan sobre su pasado y en este sentido nos sorprende una especie de dicotomía hombre-animal, en la que, por un lado, encontramos la cabeza pensante del hombre que recuerda e intenta comprender su vida actual y, por otro, se nos presenta un cuerpo que busca satisfacer los placeres o instintos básicos, muy lejos de cualquier preocupación existencial. Estas fluctuaciones entre el pasado y el presente, que se hacen más intensas conforme avanzan los textos y las historias, son parte de las inquietudes estéticas de Desnoes en la época en que escribió su primera novela. Un ejemplo de ello es la referencia a la película Hiroshima mon amour, dirigida por Alan Resnais, de la que Desnoes hizo por aquellas fechas una reseña en Lunes de Revolución; en la adaptación de Gutiérrez Alea se introduce un intertexto en una escena en la que Laura y Sergio pasan con Pablo y su pareja frente a un cartel de la película de Resnais. Tanto Hiroshima como Memorias constituyen un intento de unir cine y literatura, y de ello son conscientes Desnoes y Gutiérrez Alea. Desnoes, además, llama la atención sobre el tiempo en Hiroshima, al señalar que en la obra de Resnais el tiempo pasa de ser cronológico a

47 Kafka, 2001 [1915], 151-152.

48 Aristóteles, 1910 [siglo X], 15-16.

49 Kafka, 2001 [1915], 159.

50 Desnoes, 2006 [1965], 21-22. 
psicológico, al mezclar pasado y presente, lo que constituye uno de los aspectos más revolucionarios de la película, y lo que le da sentido de ubicuidad. ${ }^{51}$ Esto permite al escritor cubano mediar entre técnicas literarias y fílmicas para completar su texto escrito, algo que sería bien entendido por Gutiérrez Alea, como dijo Santana:

La novela Memorias... está fecundada por estas fluctuaciones emocionales que llevan a una concepción disolvente del tiempo y el espacio. El escritor bebe para la escritura de su novela lo mismo de la tradición literaria que de la innovación fílmica, lo mismo de la herencia de Proust que de las incursiones de la Nouvelle Vague. Y es esta una de las plataformas que facilitan la integración articulada de la novela al filme de Alea. ${ }^{52}$

Tanto en el argumento de La metamorfosis como en Memorias del subdesarrollo, novela y filme, es posible apreciar un interesante contraste entre lo humano y lo animal, la razón y el instinto. Por un lado, el cuerpo de Gregor presenta el comportamiento de un insecto: «sintió por primera vez en esta mañana un bienestar físico: las patitas tenían suelo firme por debajo, obedecían a la perfección, como advirtió con alegría». ${ }^{53}$ Por otra parte, en ocasiones, aunque cada vez menos, afloran sentimientos y reflexiones hacia los suyos, que a partir de entonces tendrían que trabajar para mantenerse: «Cuando se empezaba a hablar de la necesidad de ganar dinero, Gregor acababa por abandonar la puerta y arrojarse sobre el fresco sofá de cuero, que estaba junto a la puerta, porque se ponía al rojo vivo de vergüenza y tristeza». ${ }^{54}$

La distancia cada vez más nítida entre lo racional y lo instintivo, entre lo aristotélicamente humano y lo físico, va a adquirir relevancia no solo en los periodos de reflexión de Sergio sino también en su actividad, en su relación con las pocas personas con las que interactúa. Cada una de las referencias que se hagan a otras personas, sobre todo si se trata de mujeres, abundan en comentarios sobre el cuerpo, sobre reacciones físicas. En el prólogo a la edición de 2006, Desnoes aseguraba que prefiere los placeres del cuerpo a los ideales sublimes, que se encuentra más cercano a «consumir y disfrutar de una morcilla que en el asador reviente en lugar de preocuparme del gobierno del mundo y sus monarquías». ${ }^{55}$ Es más, en ocasiones, para satisfacer necesidades espirituales recurre en la novela al

51 Desnoes, 1961, 25.

52 Santana, 2010, 198.

53 Kafka, 2001 [1915], 148.

54 Kafka, 2001 [1915], 158.

55 Desnoes, 2006 [1965], 16. 
cuerpo, como en el momento en que Sergio pone remedio a su soledad y su tristeza mediante el movimiento de «las piernas, el cuerpo, los ojos, los recuerdos, todos los sentidos». ${ }^{56}$ Cuando Malabre pone la atención en una mujer es siempre el físico, por encima de elementos intelectuales o espirituales, lo que se destaca y se celebra, coincidiendo con el sesgo que Bajtin da al concepto de carnavalización. ${ }^{57}$ Por ejemplo, al describir a su empleada de hogar, repara primero en sus atributos físicos: «tenía los ojos achinados; con los ojos abiertos los párpados desaparecen por completo. No se le ve el borde carnoso del párpado cuando mira fijamente; es como si le hubieran abierto los ojos con un tajo limpio». ${ }^{58} \mathrm{Y}$, como contraste a este detallismo físico, cuando alude a una función espiritual o inmaterial, lo hace con desgana y desinterés, pues solo se le ocurre preguntarle por qué es protestante pero sin indagar más, «no fuera a pensar que me estaba burlando». ${ }^{59}$ Pero lo que demuestra de un modo evidente que lo que le interesa, entre esas dos facetas, es solo la corporal, es cuando se imagina a sí mismo en la ceremonia del bautismo de ella, «cargándola y sumergiéndola en el agua, para contemplarla luego con el vestido mojado todo adherido al cuerpo. La podría cargar con facilidad, es menuda: me da la impresión de que tiene los huesos llenos de aire». ${ }^{60}$

\section{El declive final kafkiano: del subdesarrollo al falso desarrollo}

Al final de las primeras Memorias hay un debate sobre las postrimerías. El absurdo, reflejo de los planteamientos que ya están en Kafka, llena la existencia de desesperanza. Son consecuencias lógicas del recorrido existencial que se ha trazado, de la situación kafkiana. El destino de Gregor y el de Sergio no son muy diferentes. El vacío y la muerte admiten cierto grado de identificación en la medida en que el vacío nombra lo que no es. Lo ordenado se transmuta en desorden, lo coherente en caótico, lo referencial en deconstruido. ${ }^{61}$ Gregor nunca podrá volver a la armonía familiar. Ni siquiera la hermana aguanta esa situación, hasta el extremo de que, cuando

\footnotetext{
56 Desnoes, 2006 [1965], 26

57 Bajtin, 2002 [1987], 273.

58 Desnoes, 2006 [1965], 41.

59 Desnoes, 2006 [1965], 41.

60 Desnoes, 2006 [1965], 42.

61 Laera, 2013, 117.
} 
Gregor fallece, parece que la vida de los Samsa se recupera y vuelve a la normalidad, como se documenta en las últimas líneas del relato:

\begin{abstract}
Mientras hablaban así, al señor y a la señora Samsa se les ocurrió casi al mismo tiempo, al ver a su hija cada vez más animada, que en los últimos tiempos, a pesar de las calamidades que habían hecho palidecer sus mejillas, se había convertido en una joven lozana y hermosa [...] Pensaban que ya llegaba el momento de buscarle un buen marido, y para ellos fue como una confirmación de sus nuevos sueños y buenas intenciones cuando, al final de su viaje, fue la hija quien se levantó primero y estiró su cuerpo joven. ${ }^{62}$
\end{abstract}

Sergio no muere, pero su mundo no es el mundo. En la novela de Kafka, el mundo de Gregor tampoco era el de los demás. Por eso, al morir él, todo se restablece. El universo en el que habita Sergio, al no morir, se sigue manifestando como opresivo, y su única opción es separarse de ese ambiente, que es otra forma de morir: «Salí, regresé. No soporto la casa ni la calle [...] Una isla es una trampa, la Revolución nos cogió a todos aquí dentro. No sentí ningún alivio mirando el mar. No veía nada [...] Terminó la vida, tengo que soltarlo todo: el mundo se abre debajo de mis pies, me hundo en el vacío, me vuelvo loco». ${ }^{63} \mathrm{El}$ protagonista continúa con vida, pero el foco de la narración cambia de perspectiva, como ocurría con La Metamorfosis, solo que ahora es un nuevo personaje quien sustituye a Sergio, un tal Paco, envuelto en una escena cuyo contenido nada tiene que ver con la peripecia vital de Malabre, del mismo modo que la posibilidad de buscar un marido para la hija de los Samsa desviaba la atención con respecto al destino de Gregor. Esos virajes en las escenas finales tienen algo similar, pues el punto ciego al que ha llegado Malabre conecta con la progresiva pérdida de la habilidad comunicativa de Gregor, su muerte y el olvido al que es sometido.

Pero la ironía más demoledora es la que se construye alrededor de la actividad de Paco. Ese último capítulo de las primeras Memorias, en el que desaparece Sergio, pivota en torno a la construcción de un muñeco, Yodor, sobre el que Paco descarga todas sus esperanzas económicas, pues piensa incluso viajar a los Estados Unidos para comercializarlo allí. El paralelismo no resiste a la fatal comparación: la esperanza que nunca encontró el ser humano se predica de un objeto inanimado, el cual, finalmente, también resulta un fracaso. Como el viaje al país de los sueños (el sueño americano) no es posible por el momento, Paco intenta sacar partido a su invento, llevándolo de un lado para otro:

62 Kafka, 2001 [1915], 188.

63 Desnoes, 2006 [1965], 145-147. 
En Cuba no podía vivir con Yodor. Aquí entonces había solo dos o tres compañías grandes que podían alquilar a Yodor para su propaganda. Estaban los gastos de mantenimiento y transporte [...] Ofrecí alquilarlo por tres mil pesos al mes [...] Estaba a punto de firmar el contrato cuando Guastela se metió por medio y me jodió el negocio. Les llenó la cabeza de boterías a la gente de Crusellas; les dijo que él por ese mismo dinero les hacía una campaña de publicidad por la prensa y la radio. ${ }^{64}$

Después de un efímero éxito como muñeco de espectáculos populares, el negocio terminó desbaratándose, lo que terminó también por empañar las relaciones de Paco con su esposa, quien le dijo, finalmente, con rabia: «Y pensar que tú has gastado tres mil pesos para hacer esa mierda», ${ }^{65}$ después de lo cual, Paco no tuvo más remedio que deshacerse del muñeco y desbaratarlo.

Paco se lamenta, en las últimas líneas de la novela, de la circunstancia que le ha tocado padecer, puesto que, a pesar de ser el primer empresario que creó un robot capaz de caminar, su suerte ha sido adversa y está arruinado. Aquí se ponen de manifiesto dos problemas: el primero, la ineficacia de la revolución para generar desarrollo en el país; y el segundo, que la voz del muñeco, no humano, que ha sustituido a la del protagonista, humano, no ha servido finalmente para nada. El desenlace final es el vacío y el silencio. El fracaso del individuo remite necesariamente al fracaso del sistema, que quizá en los años sesenta, cuando Desnoes terminó la novela del subdesarrollo, no era tan evidente para toda la sociedad, pero que en el cambio de siglo ya no generaba ninguna duda. El mismo Gutiérrez Alea, poco antes de morir, y al hilo de las situaciones ridículas que se presentan en la película Guantanamera, verdadero mapa de los retales o residuos de una sociedad en ruinas, relacionaba la situación de la isla con la sinrazón permanente en las obras de Kafka, y señalaba además que esa constante kafkiana es también aplicable a la historia de Cuba, no solo a aquella época de descomposición:

La realidad se comporta de una manera absurda; lo único que hacemos nosotros es constatar eso y, a partir de ahí, desarrollar una historia, pero sobre una base realista, casi documental, que al mismo tiempo es absurda. Esa idea está resumida en una frase de Virgilio Piñera: «Si Kafka hubiese nacido en Cuba, en vez de haber sido un escritor del absurdo, habría sido un escritor costumbrista». ${ }^{66}$

64 Desnoes, 2006 [1965], 176.

65 Desnoes, 2006 [1965], 180.

66 Évora, 1996, 61. 
Memorias del desarrollo, que podría revertir esta situación, ya que el protagonista es un hombre bien instalado económicamente, y acostumbrado a la libertad que ofrece un país rico que se rige por las líneas de actuación del capitalismo, acabará siendo un personaje que no es capaz de salir de los profundos desajustes que el subdesarrollo le confirió. La desarticulación del proyecto vital, que hemos visto paralelamente en el contexto de Kafka y en el de Malabre, no se revierte en la nueva novela, que rezuma desesperanza desde sus primeras páginas: «No pienso volver a correr, a ir jogging, a trotar como si tuviera la más remota idea de mi destino. Uno aprieta el paso cuando encuentra un punto en el horizonte que reclama su presencia [...] Corra o no corra, jamás llegaré a ninguna parte». ${ }^{67} \mathrm{La}$ desorientación del escritor, patente desde la primera frase de la novela, irá en aumento y su discurso recordará nuevamente a la metáfora kafkiana de la jaula y el pájaro. El nuevo protagonista está muerto en vida o, a lo más, es invisible. Le gusta pasear por las calles y tratar de convencerse de que en algún momento pueda ser aceptado, pero la verdad es que, dice, «me he vuelto invisible, dolorosamente transparente. Al principio pensé que solo las mujeres jóvenes me perforaban con la mirada, podían ver a través de mi cuerpo, como si no estuviera ante sus ojos [...] Luego descubrí que no se trataba solo de las mujeres: todos, pero todos me ignoraban, nadie me veía, veían ya al muerto». ${ }^{68}$

En la nueva novela, el narrador rememora su pasado, trata de ajustar cuentas con los desmanes que produjo el desembarco en el subdesarrollo, casi cincuenta años antes, y realiza una dura crítica a los regímenes comunistas de mitad de siglo en Europa. Las reflexiones del personaje de Memorias del desarrollo se enfocan también en la condición humana, y operan sin buscar insistentemente el mejoramiento humano en la sociedad desarrollada; a él solo le interesa discernir acerca de la presente realidad, así como de su lugar en el mundo: «Ese fue mi error. Y es mi error. Creer en el poder de la literatura, de las ideas. Las ideas valen poco, lo que valen son las cosas. Aquí en el norte aprendí una sola cosa: la literatura es entretenimiento, humo y espejos, y las ideas son sólo instrumentos. Las palabras lo explican, justifican todo, pero nada tienen que ver con la realidad». ${ }^{69}$ La mirada intimista contribuye a una nueva percepción del individuo, que

67 Desnoes, 2007, 11.

68 Desnoes, 2007, 17.

69 Desnoes, 2007, 23-24. 
luego de analizar sus errores, se sabe cada vez menos identificado con sus cohabitantes.

Como en la novela del subdesarrollo, en la siguiente entrega del cubano existen puntos en común entre el nuevo (y viejo) Sergio/Edmundo y el personaje principal de La metamorfosis, en la segunda parte del relato, que comienza a divisar el mundo circundante desde una perspectiva diferente, y que incluso deja de reconocer a algunos de los familiares más cercanos: «¿Era este todavía el padre? ¿El mismo hombre que yacía sepultado en la cama, cuando en otros tiempos, Gregor salía en viaje de negocios? ¿El mismo hombre que, la tarde en que volvía, le recibía en bata, sentado en su sillón, y que no estaba en condiciones de levantarse [...] y se dirigió a Gregor con el rostro enconado [...] levantaba los pies a una altura desusada y Gregor se asombró del enorme tamaño del suelo de sus botas». ${ }^{70}$ Poco a poco, Gregor se aleja de sus allegados, y prefiere mantenerse en la penumbra de su habitación: «la puerta permanecía algunas noches cerrada, pero Gregor renunciaba gustoso a abrirla, incluso algunas noches en las que había estado abierta no se había aprovechado de ello, sino que, sin que la familia lo notase, se había tumbado en el rincón más oscuro de la habitación». ${ }^{71}$

Memorias del desarrollo desvela un escenario que conecta con el episodio citado. El protagonista no es capaz de encajar, en el nuevo contexto, con los seres humanos que le rodean. Sergio reconoce que ocupa un lugar extraño y esa sensación le hace huir de todo aquello que pudiese relacionarle con un pasado en el que se sintió un ser social: «La sangre ya no me reclama, no me pide... Tanto mi padre como mi madre ya no esperan nada de este hijo [...] Ninguno de mis amigos sabe dónde estoy; donde encontrarme; corté las amarras [...] Ahora me cuido, tengo más cuidado cuando ando distraído. Si descubro un rostro familiar, remotamente familiar [...] cruzo inmediatamente la calle o bajo la cabeza y doblo por la primera bocacalle». ${ }^{72}$

Hacia el final del relato, el discurso de La Metamorfosis revela una voz desprovista de identidad, y resulta prácticamente imposible distinguir la condición de hombre o animal. El personaje deja de perseguir objetivos concretos para intentar llevar a cabo meras funciones vitales: moverse, desplazarse o morir. Gregor batalla, en su condición de animal herido, por volver a su encierro: «Quizá pueda darme vuelta ahora [...] Pronto descubrió

$70 \quad$ Kafka, 2001 [1915], 168.

71 Kafka, 2001 [1915], 176.

72 Desnoes, 2007, 20-21. 
que ya no se podía mover. No se extrañó por ello [...] Por lo demás, se sentía relativamente a gusto [...] En este estado de apacible y letárgica meditación permaneció hasta que el reloj de la torre dio las tres de la madrugada. A continuación, contra su voluntad, su cabeza se desplomó sobre el suelo y sus orificios nasales exhalaron el último suspiro». ${ }^{73}$ La muerte, en este caso, se plantea como la única alternativa para el logro de la tan anhelada libertad. Gregor deja de esperar el retorno a su estado inicial y Sergio/Edmundo parece acercarse, cada vez más, al final de la agonía. Para ambos personajes, seguir vivos significa el encierro, la cárcel, mientras que el abandono de sus cuerpos podría ser equivalente a la liberación del ave enjaulada.

Los personajes de ambas obras se enfrentan a la pérdida irreparable de la identidad. Gregor, convertido en insecto, se percata de que no volverá a ser un hombre y, al sentirse cada vez menos identificado con quienes habían sido sus iguales, espera desaparecer, como única vía de escape al cautiverio. En sus últimos momentos, Gregor muestra alivio al acercarse a la muerte: «le dolía todo el cuerpo, pero le parecía como si los dolores se hiciesen más y más débiles y, al final, desaparecieron por completo. Apenas sentía ya la manzana podrida de su espalda y la infección que producía a su alrededor, cubiertas ambas por un suave polvo. Pensaba en su familia con cariño y emoción, su opinión de que tenía que desaparecer era, si cabe, aún más decidida que la de su hermana». ${ }^{74}$ Por su parte, Edmundo es consciente de que no podrá mejorar el presente. Contrariamente a lo esperado por el personaje, su estadía en el desarrollo contribuye al vaciamiento de los sentimientos e ideales que le llevaron a buscar una esperanza en el desarrollo exterior. Desesperanzado, el narrador deja de indagar acerca de la sociedad, para dedicarse a buscar algo en qué apoyarse, que no son las personas, la familia, los amigos: «Un perro: pensé mientras me acostumbraba a convivir con solo mi imagen en el espejo [...]; el perro es la única criatura en toda la creación que ha establecido una verdadera intimidad con la mujer y con el hombre [...], el perro vive en simbiosis con los humanos. Por eso pensé que debía conseguirme un perro». ${ }^{75} \mathrm{El}$ panorama de deterioro y abandono que experimentan Gregor y Edmundo deriva inexorablemente en el quebranto de la voz. En Memorias del desarrollo, el protagonista se aparta de la búsqueda de explicaciones lógicas, y se inclina a reflexiones filosóficas y al silencio. A diferencia de Memorias del subdesarrollo, el protagonista

73 Kafka, 2001 [1915], 182-183.

74 Kafka, 2001 [1915], 183.

75 Desnoes, 2007, 12-13. 
deja de elaborar discursos reflexivos para pasar a una etapa de huida: de su casa, de su trabajo, de su historia y de sus miedos; se instala en una cabaña en el medio del campo, lejos de la humanidad, cerca de la naturaleza y de los animales. Gregor, desde la ventana del cuarto al que ha sido confinado, examina el mundo sin ser visto. Edmundo, por su parte, describe con minuciosidad los aspectos de la naturaleza con los que comparte sus últimos días: «Un groundhog, una obesa marmota se deleita en el césped [...], en cuanto me ve abrir la puerta huye [...] Tengo la sospecha, me temo que la marmota se ha establecido, vive bajo la cabaña». ${ }^{76}$

Del mismo modo que en las primeras Memorias aparecía un nuevo personaje al final de la historia, que complementaba de algún modo el sentido kafkiano de la mirada desconcertada y desesperanzada del primer Sergio, en las del desarrollo se da cita un nuevo contrapunto, que produce un efecto de extrañamiento mucho más radical que el de aquel Paco anterior con su juguete Yodor. En las primeras Memorias, los nuevos personajes estaban desconectados del protagonista pero pertenecían a la misma ficción. En la nueva novela, es la hija de Desnoes la que ocupa la voz narrativa en el último capítulo y busca denodadamente a su padre Edmundo, hasta que lo encuentra, viejo y enfermo, y poco después muere. Este Edmundo/Sergio de las últimas páginas ya no puede dedicarse más a encontrar un resquicio identitario, porque su destino coincide - ahora sí- con el de Gregor Samsa. La muerte impide el autoesclarecimiento, pero a la vez lo explica todo. Edmundo/Sergio parece, finalmente, haber llegado a una meta, insuficiente pero válida: la única solución parece ser la liberación del cuerpo; sin cuerpo no hay prisión, ni desencanto, ni sufrimiento. Animalización, pérdida de voz, corporalidad sin conciencia, desintegración: este es el proceso que conforma la búsqueda inútil de una identidad esquiva. Kafka llegó a Cuba de la mano de Virgilio Piñera, quien sintetizó de un modo muy sutil la realidad de ese proceso de aniquilación, al afirmar que «uno de los pilares esenciales del arte de Kafka es su lúcido olvido del individuo (aisladamente considerado) y su énfasis absoluto sobre lo objetivo del mundo». ${ }^{77}$ De ese modo, a través de un procedimiento puramente técnico, el escritor checo generó las claves para la interpretación de cualquier universo en el que se necesitara historiar la pérdida, la derrota, la resignación ante lo inevitable, o también la desidia para la lucha. En clave desnoana, cabe decir que tanto el Sergio burgués del subdesarrollo, desplazado y desclasado en la nueva

76 Desnoes, 2007, 185.

77 Piñera, 2013, 119. 
configuración revolucionaria, como el personaje que ha buscado su identidad fuera de la isla para volver a encontrarse en la nada cotidiana, aprenden la lección estética de Kafka. Este disolvió al individuo en el mundo físico a través de sus alegorías; Desnoes recogió el estatuto simbólico del checo para monitorear su propia desintegración.

Recibido, 18 de marzo de 2019 Segunda versión, 4 de julio de 2019

Aceptado, 8 de agosto de 2019

\section{Referencias bibliográficas}

Arce, Rafael, «Del símbolo a la metonimia vía Kafka. Mundo animal de Antonio di Benedetto», Acta Literaria, 52, Concepción, 2016. Disponible en: http:// dx.doi.org/10.4067/S0717-68482016000100007 [Consultado: 03/01/2019].

Arenas, Reinaldo, «La isla en peso con todas sus cucarachas», Mariel, 2, Nueva York/Miami, 1983, 20-24.

Aristóteles, La Política, traducción de Pedro Simón Abril, Madrid, Ediciones Nuestra Raza, 1910 [s. IV a. C.].

Bajtin, Mijaúl, La Cultura Popular en la Edad Media y el Renacimiento: el contexto de François Rabelais, Madrid, Alianza Editorial, 2002 [1. $\left.{ }^{\mathrm{a}} \mathrm{ed} .1987\right]$.

Bell, Daniel, El fin de las ideologías, Madrid, Tecnos, 1964 [1. a ed. 1960].

Bell, Daniel, Las contradicciones del capitalismo, Madrid, Alianza Editorial, 2006a [1. ${ }^{\text {a }}$ ed. 1976].

Bell, Daniel, El advenimiento de la sociedad postindustrial, Madrid, Alianza Editorial, 2006b [1. ${ }^{\mathrm{a}}$ ed. 1973].

De la Campa, Román, «Memorias del subdesarrollo. Novela/Texto/Discurso», Revista Iberoamericana, LVI:152-153, Pittsburgh, 1990, 1039-1054.

Desnoes, Edmundo, «¿Evolución o Revolución?», Lunes de Revolución, 65, La Habana, 1960, 20-21.

Desnoes, Edmundo, «Año dieciséis después de Hiroshima», Lunes de Revolución, 97, La Habana, 1961, 24-25.

Desnoes, Edmundo, Punto de vista, La Habana, Instituto del Libro, 1967.

Desnoes, Edmundo, Memorias del subdesarrollo, Sevilla, Mono Azul, 2006 [1. ${ }^{\mathrm{a}}$ ed. 1965].

Desnoes, Edmundo, Memorias del desarrollo, Sevilla, Mono Azul, 2007.

Domínguez, Daylet, «Lectura en dos tiempos: cuerpos y subjetividades en Memorias del subdesarrollo y El Rey de la Habana», Revista de Estudios Hispáni$\cos , 45: 3$, Saint Louis, 2011, 571-592.

Edwards, Jorge, Persona non grata, edición de Ángel Esteban y Yannelys Aparicio, Madrid, Cátedra, 2015 [1. ${ }^{\mathrm{a}}$ ed. 1973]. 
Esteban, Ángel y Aparicio, Yannelys, «Pretecnología en tiempos tecnológicos: "Rumba Palace" de Miguel Mejides», en Noguerol, Francisca; López, María Ángeles y Sánchez, Vega (eds.), Letras y bytes. Escrituras y nuevas tecnologías, Kassel, Edition Reichenberger, 2015, 185-203.

Évora, José Antonio, Tomás Gutiérrez Alea, Madrid, Cátedra, 1996.

Fernández Retamar, Roberto, «Hacia una intelectualidad revolucionaria en Cuba», Casa de las Américas, 40, La Habana, 1967, 4-18.

Fernández Retamar, Roberto, Para una teoría de la literatura hispanoamericana, Bogotá, Publicaciones del Instituto Caro y Cuervo, 1995 [1. a ed. 1976].

Fornet, Ambrosio, «El intelectual en la Revolución», en Benedetti, Mario et al. (eds.), Literatura y arte nuevo en Cuba, Barcelona, Laia, 1977, 33-39.

Garbatzky, Irina, «Supervivencia de las cucarachas. Kafka en Cuba a finales del siglo XX», 452 $2^{\circ} F, 17$, Buenos Aires, 2017, 47-65.

García-Muñoz, José Alpiniano, El tomismo desdeñado, Bogotá, Planeta Colombiana, 2012.

Goytisolo, Juan, Señas de identidad, México, Joaquín Mortiz, 1966.

Guevara, Ernesto, Obra revolucionaria. El hombre y el socialismo en Cuba, México, Editorial Era, 1968.

Jameson, Frederic, Postmodernism, or the Cultural Logic of Late Capitalism, Londres, Duke University Press, 1991.

Jiménez Martínez, Mauro, Teoría y crítica de la novela existencialista, Madrid, Universidad Complutense, 2011.

Kafka, Franz, La metamorfosis y otros relatos, Madrid, Cátedra, 2001 [1. a ed. 1915].

Laera, Rodrigo, «La preocupación por la muerte», Problemata, 4:1, João Pessoa, 2013, 110-133.

Martínez Salazar, Elisa y Yelin, Julieta, Kafka en las dos orillas. Antología de la recepción crítica española e hispanoamericana, Zaragoza, Universidad de Zaragoza, 2013.

Melo Ruiz, Héctor Alfonso, «Memorias del subdesarrollo (1968): ante el rostro de la muchedumbre desde las paradojas del cine documental», A Contracorriente. Una revista de estudios latinoamericanos, 15:1, Raleigh, 2017, 127-148.

Menton, Seymour, Caminata por la literatura latinoamericana, México, Fondo de Cultura Económica, 2002.

Oviedo, José Miguel, «Un personaje de Camus en La Habana», Plural, 55, México, 1976, 64-67.

Peris, Jaume, «Ironía, ambivalencia y política en Memorias del subdesarrollo, de Edmundo Desnoes», Rilce, Revista de Filología Hispánica, 27:2, Pamplona, 2011, 424-440.

Piñera, Virgilio, «El secreto de Kafka», en Martínez Salazar, Elisa y Yelin, Julieta (coords.), Kafka en las dos orillas, Zaragoza, Universidad de Zaragoza, 2013, 119-124. 
Rojas, Rafael, Motivos de Anteo. Patria y nación en la historia intelectual de Cuba, Madrid, Editorial Colibrí, 2008.

Rojas, Rafael, El estante vacío. Literatura y política en Cuba, Barcelona, Anagrama, 2009.

Sánchez Mejías, Rolando, La noche profunda del mundo, La Habana, Letras Cubanas, 1993.

Santana Fernández de Castro, Astrid, Literatura y cine. Lecturas cruzadas sobre las Memorias del subdesarrollo, Santiago de Compostela, Universidad de Santiago de Compostela, 2010.

Taccetta, Natalia y Martín Peña, Fernando, «Memorias del subdesarrollo (Tomás Gutiérrez Alea, 1968)», Solocortos.com. Cortometrajes On Line, Argentina, 10 de marzo de 2006. Disponible en: http://www.solocortos.com/RevistaSC. aspx?nroArticulo=210, [Consultado: 10/01/2019].

Varela, Fabiana Inés, «Cuerpos invadidos: Cuerpo y corporalidad en algunos relatos de Antonio Di Benedetto», Revista de Literaturas Modernas, 37-38, Cuyo, 2007, 209-228.

Yelin, Julieta, «Kafka en Argentina», Hispanic Review, 78:2, Filadelfia, 2010, 251-273.

Yelin, Julieta, La letra salvaje. Ensayos sobre literatura y animalidad, Rosario, Beatriz Viterbo, 2015. 